\title{
108. The Crystal Structure of Axinite Revised
}

\author{
By Tei-ichi Ito, M.J.A., Yoshio TakéUchi,*) Toru Ozawa,*) \\ Takaharu ARAKI,**),†) Tibor ZoLTAI,**) \\ and J. J. FINNNEY***) \\ (Comm. June 10, 1969)
}

The crystal structure of axinite, $\mathrm{H}(\mathrm{Fe}, \mathrm{Mn}) \mathrm{Ca}_{2} \mathrm{Al}_{2} \mathrm{BSi}_{4} \mathrm{O}_{16}$, was investigated by Ito and Takéuchi (1952) on the assumption that boron atoms in the structure form separate $\mathrm{BO}_{3}$ groups like tourmaline (Ito, 1950; Ito and Sadanaga, 1951; vide Buerger et al., 1962). The structure then deduced by taking account of Patterson projections consists of separate $\mathrm{Si}_{4} \mathrm{O}_{12}$ and $\mathrm{BO}_{3}$ groups bound together by $\mathrm{Fe}, \mathrm{Al}$ and $\mathrm{Ca}$ atoms. Although the structure was crystallo-chemically reasonable, the residual $R$ could not be reduced to less than 0.35 for all the reflections observed. Since axinite is one of those common silicate minerals whose crystal structure has not been refined, it has been thoroughly reinvestigated using modern techniques.

The specimens used are from Woodlake, California (Type collection \#9620, Colorado School of Mines). Chemical analysis by an electron microprobe gives the $\mathrm{Fe}$ to $\mathrm{Mn}$ ratio of the specimen to be approximately unity. The lattice constants of the triclinic crystal are

$$
\begin{array}{ll}
\mathrm{a}=7.1566 \pm 0.0015, & \alpha=91.75^{\circ} \pm 0.83 \\
\mathrm{~b}=9.1995 \pm 0.0020, & \beta=98.14^{\circ} \pm 0.02 \\
\mathrm{c}=8.9585 \pm 0.0022, & \gamma=77.30^{\circ} \pm 0.02
\end{array}
$$

and the unit cell contains two formula units. Three dimensional intensities were collected by a scintillation counter using an equiinclination single-crystal diffractometer, $\mathrm{MoK}_{\alpha}$ radiation and a pair of balanced $\mathrm{Zr}-\mathrm{Y}$ filters. A total of 3315 independent reflections were measured up to $\sin \theta=0.5000$. The intensities were corrected for Lorentz-polarization and transmission with the aid of C. W. Burnham's computer program (Burnham, 1966). The $N(z)$ test of Howells, Phillips and Rogers (1950), using all reflections, disclosed that the structure is centric, confirming the previous result by Ito and Takéuchi.

*) Mineralogical Institute, Faculty of Science, University of Tokyo.

**) Department of Geology and Geophysics, University of Minnesota, Minneapolis, Minnesota, U.S.A.

***) Department of Geology, Colorado School of Mines, Golden, Colorado, U.S.A.

†) Present address: Central Research Laboratory, Tekkosha, Musashinoshi, Tokyo. 
We first attempted to refine the atomic coordinates given by Ito and Takéuchi based upon new intensity data, but it was not possible to improve the residual index any further. The previous structure analysis was mainly carried out in the a-axis projection. However, the a-axis projection of three-dimensional Patterson function of axinite is very characteristic in that all of the pronounced peaks are arranged parallel to $(04 \overline{4})$ and $(022)$. Thus we suspected that, at least the locations of heavy atoms are concerned, the structure might be one of the possible homometric ones. Therefore we decided to redetermine the structure by applying some direct method. Although the asymmetric unit of axinite contains 25 atoms including heavy atoms, a preliminary calculation showed that 436 reflections have $|\mathrm{E}|$ values bigger than 1.50. Among them, $|\mathrm{E}|$ 's of 214 reflections are bigger than 1.80 , which is equivalent to $|\mathrm{U}|=0.3$, and those of 9 reflections exceed 3.0. We then tried the Karle-Karle symbolic addition procedure (Karl and Karl, 1966). The initial set of reflections used for this statistical method is listed in Table I.

Table I. Starting set of reflections used for the symbolic addition procedure

\begin{tabular}{|c|c|c|c|c|c|}
\hline $\mathrm{h}$ & $\mathrm{k}$ & 1 & $/ \mathrm{E} /$ & sign & \\
\hline 2 & 1 & 8 & 2.98 & +1 & \multirow{3}{*}{ from choice of origin } \\
\hline$\overline{1}$ & 8 & $\overline{4}$ & 2.93 & - & \\
\hline 4 & 8 & $\overline{7}$ & 3.23 & +1 & \\
\hline$\overline{5}$ & 4 & $\overline{1}$ & 3.01 & $\mathrm{a}$ & becomes -1 \\
\hline 3 & 2 & 5 & 2.50 & b & \multirow{2}{*}{ becomes $b=c=+1$} \\
\hline$\overline{7}$ & 0 & 3 & 2.64 & c $\}$ & \\
\hline 4 & 4 & 2 & 3.00 & $\mathrm{e}$ & becomes +1 \\
\hline
\end{tabular}

A list of $\Sigma_{2}$ equations was prepared using Ashida's program (Ashida, 1964) and possible combinations $\mathrm{E}_{h}, \mathrm{E}_{k}, \mathrm{E}_{h+k}$ with $|\mathrm{E}| \geq 1.5$ by means of the method of A. L. Bednowitz modified by H. Takeda for HITAC $5020 \mathrm{E}$. At first step, the procedure was confined to those reflections with $|\mathrm{E}| \geq 1.80$, and signs which have probability bigger than $99.7 \%$ were assumed to be acceptable. After hand calculations, $a$ was found to be negative, $e$ to be very probably positive, and $b$ is equal to $c$. Then for 214 reflections, signs were allotted including symbols, $b, c$ and $e$. At this stage, to avoid unnecessary confusion in further steps, a three-dimensional Fourier synthesis was calculated using 214 reflections for each of the eight possible combinations of signs, $b, c$ and $e$. Although in the eight Fourier diagrams, the distributions of peaks, which are presumably of heavy atoms, are much alike, a closer examination revealed that two of the eight diagrams were most probable from crystallo-chemical view point. As next 
[Vol. 45,

step, the Karle-Karle symbolic procedure was extended to those reflections with $|\mathrm{E}| \geq 1.50$, and $e$ was proved to be positive, $b$ and $c$ positive. This combination of signs agreed with one used to calculate one of the two probable Fourier diagrams above mentioned. Among 436 reflections with $|\mathrm{E}| \geq 1.50$, signs for 431 reflections were thus determined and they were used to calculate a three-dimensional $\mathrm{E}$ map which gave well defined peaks. By taking account of peak heights and bond lengths commonly found in silicates, the map was successfully interpreted and coordinates of atoms excluding boron were deduced. The coordinates were immediately refined with the modified Busing-Martin-Levy least-squares program. At the stage of residual $R=0.15$, a three-dimensional difference Fourier map was calculated and locations of boron atoms were unambiguously deter-

Table II. Atomic parameters of axinite (at the stage of $R=0.058$ )

\begin{tabular}{|c|c|c|c|c|}
\hline Atom & $\mathrm{x}$ & $\mathrm{y}$ & $\mathrm{z}$ & $\mathrm{B}$ \\
\hline $\mathrm{Fe}$ & 0.76876 & 0.59043 & 0.11208 & 0.5 \\
\hline $\mathrm{Ca} 1$ & 0.74663 & 0.34787 & 0.39559 & 0.2 \\
\hline $\mathrm{Ca} 2$ & 0.18328 & 0.10044 & 0.08357 & 0.3 \\
\hline Al 1 & 0.0529 & 0.8010 & 0.2544 & 0.0 \\
\hline Al 2 & 0.3521 & 0.9362 & 0.4214 & 0.0 \\
\hline $\mathrm{Si} 1$ & 0.2119 & 0.4504 & 0.2357 & 0.0 \\
\hline $\mathrm{Si} 2$ & 0.2190 & 0.2746 & 0.5241 & 0.0 \\
\hline $\mathrm{Si} 3$ & 0.6995 & 0.2553 & 0.0112 & 0.0 \\
\hline $\mathrm{Si} 4$ & 0.6412 & 0.0189 & 0.2304 & 0.0 \\
\hline O 1 & 0.0564 & 0.6038 & 0.1952 & 0.3 \\
\hline O 2 & 0.2328 & 0.3385 & 0.0982 & 0.4 \\
\hline O 3 & 0.4202 & 0.4863 & 0.3132 & 0.3 \\
\hline O 4 & 0.1353 & 0.3736 & $0 \cdot 3712$ & 0.5 \\
\hline $\mathrm{O}$ & 0.0221 & 0.2418 & 0.5641 & 0.2 \\
\hline O 6 & 0.3260 & 0.3795 & 0.6455 & 0.2 \\
\hline O 7 & 0.3808 & 0.1272 & 0.4963 & 0.2 \\
\hline O 8 & 0.5370 & 0.3435 & 0.8771 & 0.2 \\
\hline O 9 & 0.8762 & 0.1542 & 0.9332 & 0.3 \\
\hline O 10 & 0.7687 & 0.3650 & 0.1391 & 0.4 \\
\hline O 11 & 0.6039 & 0.1346 & 0.0862 & 0.5 \\
\hline O 12 & 0.4361 & 0.9815 & 0.2440 & 0.2 \\
\hline O 13 & 0.7204 & 0.0994 & 0.3840 & 0.3 \\
\hline O 14 & 0.7944 & 0.8739 & 0.1782 & 0.2 \\
\hline O 15 & 0.3253 & 0.7459 & 0.3541 & 0.2 \\
\hline $\mathrm{OH}$ & 0.0966 & 0.9957 & 0.3231 & 0.2 \\
\hline B & 0.4615 & 0.6353 & 0.2857 & 0.1 \\
\hline \multicolumn{5}{|c|}{ Standard error } \\
\hline $\mathrm{Fe}$ & 0.00010 & 0.00007 & 0.00008 & \\
\hline $\mathrm{Ca}$ & 0.00012 & 0.00009 & 0.00009 & \\
\hline $\mathrm{Al}$ & 0.00017 & 0.00013 & 0.00014 & \\
\hline $\mathrm{Si}$ & 0.00016 & 0.00012 & 0.00012 & \\
\hline $\mathrm{B}$ & 0.0006 & 0.0005 & 0.0005 & \\
\hline $\mathrm{O}$ & 0.0004 & 0.0003 & 0.0003 & \\
\hline
\end{tabular}


mined. The least-square refinements were further carried out and at the present stage the $R$ value was reduced to 0.07 for all 3315 reflections. If we exclude 80 stronger reflections which are apparently affected by secondary extinction effect, the $\mathrm{R}$ is calculated to be 0.058. Atomic parameters are listed in Table II. If we compare the structure thus determined with the previously proposed structure, one to be discarded, the arrangements of heavy atoms in the a-axis projection are quite similar. So far as the a-axis Patterson projection is concerned, the locations of atoms including oxygen seem to fit it even better than those of the new structure.

The structure of axinite now revised contains $\mathrm{Si}_{2} \mathrm{O}_{7}$ groups. The salient feature of the structure is that four of the pyrosilicate groups are joined together by boron atoms with tetrahedral coordination to form a large boro-silicate group having the chemical composition $\mathrm{B}_{2} \mathrm{Si}_{8} \mathrm{O}_{30}$ (Fig. 1). In the group, two $\mathrm{Si}_{2} \mathrm{O}_{7}$ groups and two $\mathrm{BO}_{4}$ tetrahedra form a hexagonal ring which has a center of symmetry. This ring is approximately parallel to $(\overline{1} 21)$, which is one of the

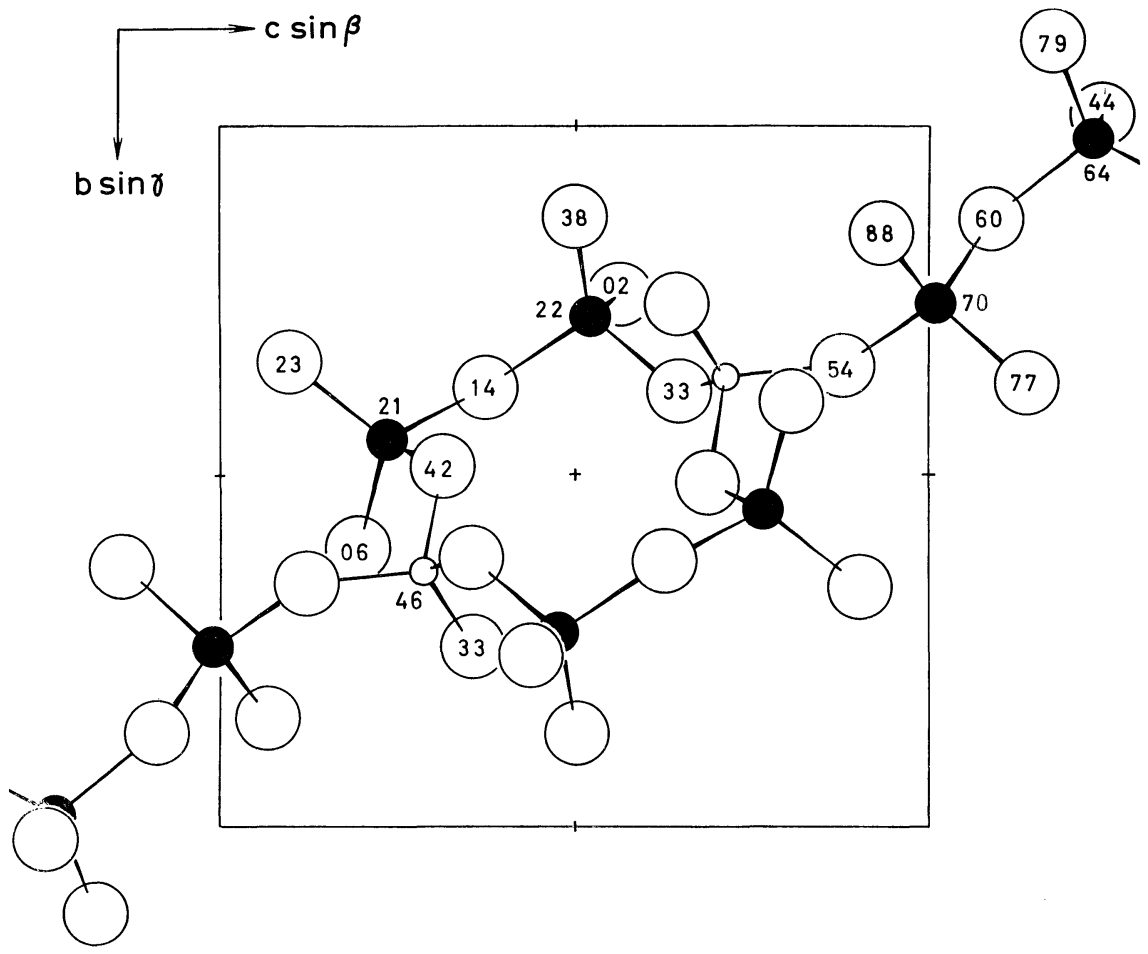

Fig. 1. The figur shows the structure only in parts, illustrating the existence of the $\mathrm{B}_{2} \mathrm{Si}_{8} \mathrm{O}_{30}$ ring in the axinite structure. Large open circles denote oxygen atoms. Small open and black circles denote silicon and boron atoms respectively. Numbers express in fraction of the a-length the hight of each atom. Projection on the a-plane. 
[Vol. 45,

characteristic forms of axinite and commonly denoted by $s$. The boro-silicate groups are bound together by $\mathrm{Al}, \mathrm{Fe}$ and $\mathrm{Ca}$ atoms. The arrangement of these cation polyhedra shows another salient characteristics of the structure. Namely four aluminum-oxygen octahedra and two iron-oxygen octahedra, each having fairly regular shape, form a 'finite' chain by sharing edges. These finite chains are joined together by $\mathrm{Ca}$ atoms, each has an octahedral coordination but elongated along [011]. Further refinement of the structure is in progress by taking account of anisotropic temperature factors and extinction corrections. The process of intensity data and calculation of threedimensional Patterson function were performed with the University of Minnesota's CDC 6000 computer, and all subsequent computations for structure analysis and refinements on HITAC $5020 \mathrm{E}$ at the Computing Center of the University of Tokyo.

\section{References}

T. Ashida (1964): Universal Program System for Crystallographic Computations (edited by T. Sakurai) (I), p. 43, Cryst. Soc. Japan.

M. J. Buerger, Charles W. Burnham, and Donald R. Peacor (1962): Assessment of the several structures proposed for tourmaline. Acta Cyrst., 15, 583-590.

Burnham, Charles W. (1966): Computation of absorption corrections, and the significance of end effect. Am. Mineral., 51, 159-167.

E. R. Howells, D. C. Phillips, and D. Rogers (1950): Probability distribution of $\mathrm{X}$-ray intensities. II. Experimental investigation and the X-ray detection of centres of symmetry. Acta Cryst., 3, 210-217.

T. Ito (1950): X-ray Studies on Polymorphism. Tokyo, p. 144.

T. Ito and R. Sadanaga (1951): A Fourier analysis of the structure of tourmaline. Acta Cryst., 4, 385-390.

T. Ito and Y. Takéuchi (1952): The crystal structure of axinite. Acta Cryst., 5, 202-208.

J. Karle and I. L. Karle (1966): The symbolic addition procedure for phase determination for centrosymmetric and noncentrosymmetric crystals. Acta Cryst., 21, 849-859. 